\title{
Architecture of Service-Oriented Training for the Comprehensive Ability
}

\author{
Wang Lei ${ }^{1}$, Xia Xu-hui ${ }^{1,2^{*}}$, Liu Xiang ${ }^{2}$, Cao Jianhua ${ }^{2}$, Liu Junwei ${ }^{3}$ \\ 1. National Demonstration Center for Experimental Mechanical Education, Wuhan University of Science and Technology, \\ Wuhan, 430081, China \\ 2. Engineering Training Center, Wuhan University of Science and Technology, Wuhan, 430081, China \\ 3. Graduate school, Wuhan University of Science and Technology, Wuhan, 430081, China \\ Corresponder: xiaxuhui@wust.edu.cn
}

\begin{abstract}
Based on the analysis of the present situation of the development of manufacturing service and the training needs of college students' comprehensive ability, the connotation of service-oriented comprehensive ability training is put forward. The overall architecture of service-oriented comprehensive ability training system is constructed. The teaching content, teaching platform and teaching team building in the serviceoriented comprehensive ability training system are analyzed, providing a theoretical basis for the systematic research and application of service oriented comprehensive ability training mode of for undergraduate.
\end{abstract}

Keywords-Undergraduate; Comprehensive ability; Serviceoriented training; Connotation; Architecture

\section{INTRODUCTION}

The comprehensive ability training for undergraduates is an important practical teaching link in the engineering major of colleges and universities. It is a preparatory education for training high-quality engineering talents with engineering quality and innovative ability in the manufacturing industry. In recent years, with the integration of "manufacturing" and "service", manufacturing enterprises have been upgrading to the service transformation [1], which has improved the requirements for the engineering practice ability and innovation ability of engineering college students continuously [2]. The higher engineering colleges and universities have begun to pay more attention to the comprehensive ability training, and have greatly promoted the construction of hardware facilities for comprehensive ability training [3]. However, it is not enough to increase the hardware input and blindly add the content of courses to train the comprehensive abilities that meet different professional needs. Under the premise of improving the students' practical ability and innovation ability, attention should be paid to the students' professional differences and individual needs in the teaching curriculum and teaching mode of undergraduates' comprehensive ability training, and the individualized and innovative talents training mode should be carried out. Drawing on the project teaching mode of innovative talents training in foreign universities [5], as the provincial engineering training demonstration center of Hubei Province, Wuhan University of Science and Technology (WUST) Engineering Training Center started to carry out "personalized training", "CDIO based modular training" and other practical training models for some training students, and have achieved certain good training effect. With the limited time and teacher team set by the big engineering perspective and the credit system, in order to more scientifically carry out comprehensive ability training service for undergraduates, Institute of Mechanical Automation of WUST joined the Engineering Training Center conducted reform and practical study of service oriented comprehensive ability training system for undergraduates, which illustrated the connotation of service-oriented comprehensive ability training and its service system architecture, guaranteeing the effective operation of the training service system for the improvement of undergraduates' comprehensive ability.

\section{CONNOTATION OF SERVICE-ORIENTED COMPREHENSIVE ABILITY TRAINING}

With the advance of the new industrialization reform in China, "service" has become a part of the whole process of production. By integrating "service" and "manufacturing", manufacturing enterprises cooperate with each other to provide manufacturing process services at the same level, and cooperate to complete the manufacture of products. The production service enterprises provide the business process level services covering the whole life cycle of the product for the manufacturing enterprises and customers, providing a product service system for customers. This deeper integration mode of manufacturing and service is called "service oriented manufacturing"[9]. The presentation of this model reflects the industrial background of the service-oriented development of manufacturing industry. The comprehensive ability training of undergraduates belongs to the category of engineering education, while practical education should return to industry and cultivate advanced engineering talents for the development of industry. From this perspective, the comprehensive ability training of undergraduates is a preparatory education for the training of high-level professionals in the manufacturing industry. The model of undergraduates' comprehensive ability training and education should follow the development trend of the manufacturing industry. The own development model should be actively adjusted and the training mode should be transformed to the service-oriented comprehensive ability training mode. 
The comprehensive ability training service of undergraduates is a new practice teaching form of integrated ability training, which integrating engineering training and service. It is a new teaching mode and comprehensive ability training organization mode. Based on the existing practical ability training CDIO education mode and service thought, the service oriented comprehensive ability training can be initially understood as: service-oriented comprehensive ability training is aimed at the value added of stakeholders in the students' knowledge value chain. Through the practice of the integration of product manufacturing and service, the full participation of the students, the knowledge services and operational services of the teaching service providers, such as theory / technology / technology, etc., the integration of service resources such as practical equipment, teaching service is realized, the effective implementation of comprehensive ability training service system is realized, and the value of comprehensive ability training and the value of students are realized.

\section{CONSTRUCTION OF SERVICE ORIENTED COMPREHENSIVE ABILITY TRAINING SYSTEM}

\section{A. General architecture of service integrated ability training system}

The service oriented comprehensive ability training is based on comprehensive training service and service oriented comprehensive ability training, which forms a complex of knowledge value increment through the integration of product manufacturing, service supply and knowledge in the practice module. It is not only a new teaching mode, but also a new organization mode of comprehensive ability training, with its architecture shown in Fig. 1.

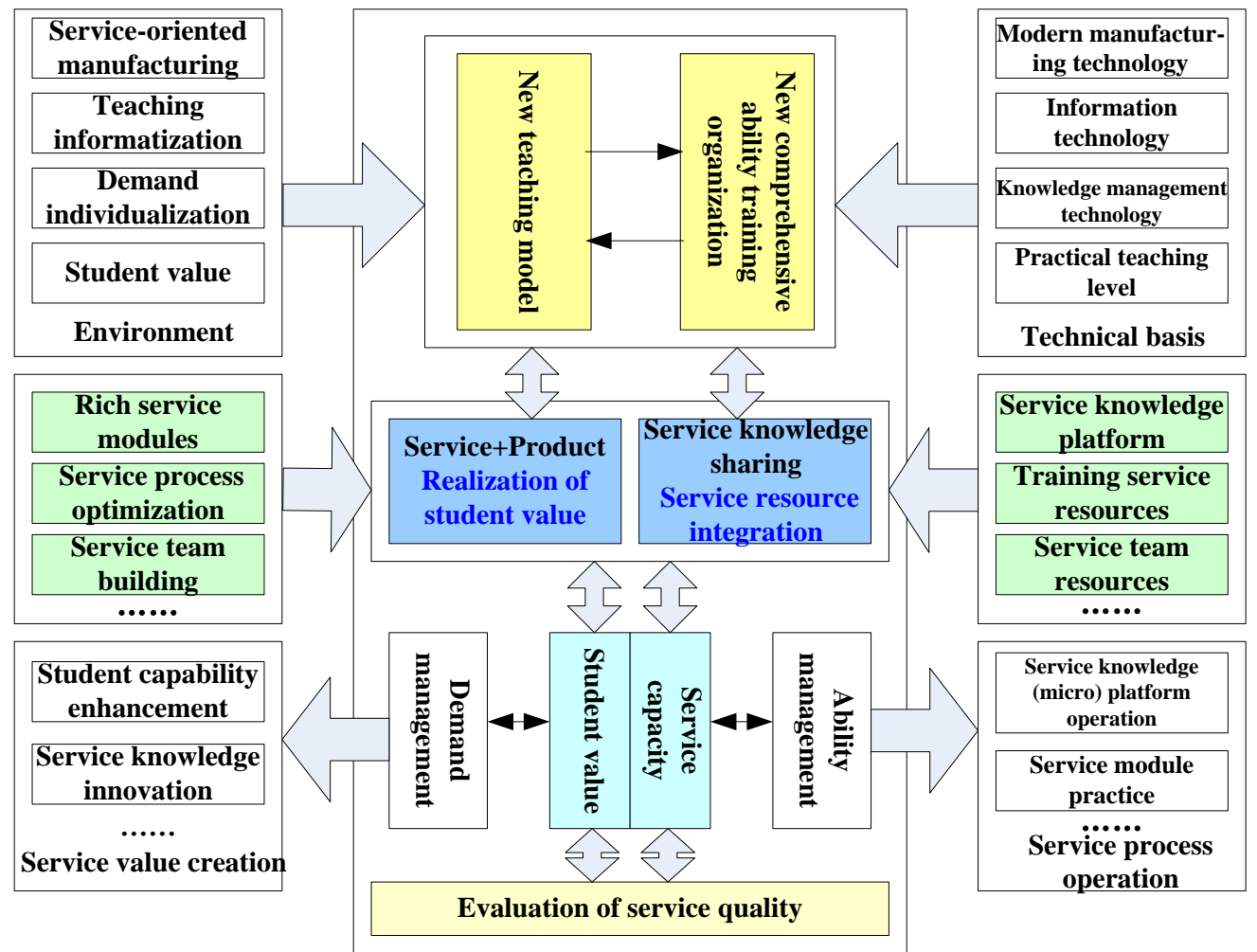

Fig. 1. Architecture of service-oriented capability training system

\section{B. Teaching content of service-oriented comprehensive ability training}

Under the large environment of the credit system, according to different majors, the training program of practical teaching talents is optimized, the practical innovation credits are set up, the students' total credits are included, and the teaching system of "three levels, three abilities and multi modules" is implemented. The three levels include engineering cognition and basic training, basic discipline skills training and multi-disciplinary knowledge integration practice, comprehensive innovation and practical training. Three ability refer to basic practical ability, professional practical ability and practical innovation ability. Multiple modules, namely integrated ability training, are divided into 1-2 independent and interrelated modules. According to the minimum requirements of their own majors, students complete the operation training of the corresponding modules, and get the scores and corresponding ability levels. Interested students can continue to choose the next level of training modules, like game clearance, and in the case of resource permission, all module selection and time arrangement are determined by the students themselves. What to learn and when to learn is determined by the students themselves, which greatly stimulated students' enthusiasm for autonomous learning. Moreover, students who are particularly interested in comprehensive ability training can choose to practice innovation modules to acquire innovative credits and participate in various competitions after completing the training practice, so that they can excel in skills, which realizes 
educating students in accordance with their aptitude, and greatly improving students' practical ability and comprehensive innovation power.

\section{Service oriented comprehensive ability training teaching platform}

Combining the characteristics of service oriented comprehensive ability training, the hardware facilities of the knowledge service platform are perfected, the knowledge service software platform is optimized, and the third party service providers and the rich campus wireless network are used to build the micro platform for the comprehensive ability training service. The service oriented knowledge service platform for comprehensive ability training with service micro platform is shown in Fig. 2, which builds platform knowledge library including basic knowledge library, training video library, etc.

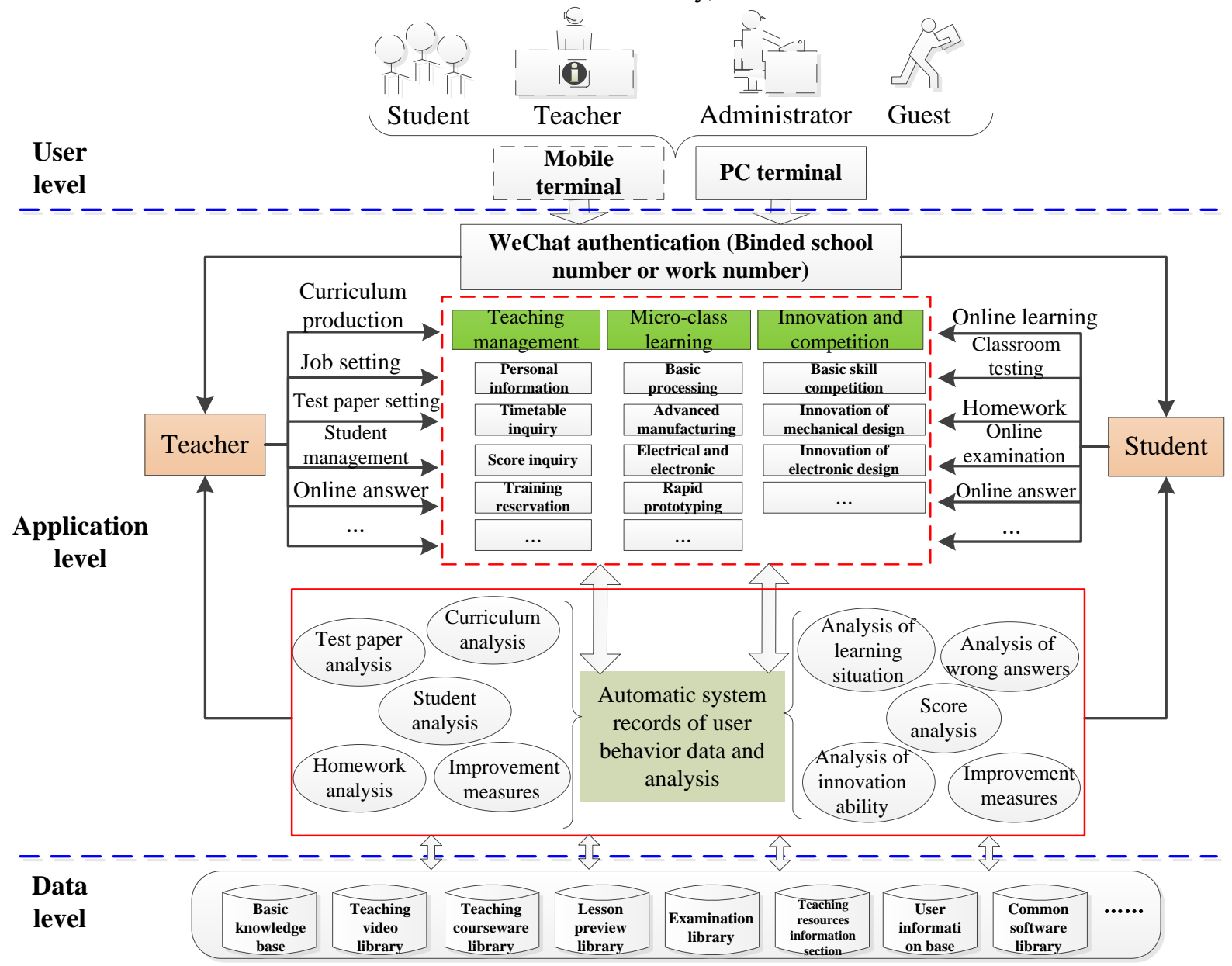

Fig. 2. Service oriented comprehensive capability training microplatform architecture.

\section{Service oriented comprehensive ability training teaching team}

According to the service oriented comprehensive ability training and the teaching goal of module, from the perspective of resource sharing and complementary advantages (such as technical advantage, capital advantage, market advantage, etc.), a double team model of cross organization service oriented comprehensive ability training is constructed. From the perspective of organizational relationship, individual relationship and platform sharing, the characteristics, operating mechanism and methods of the acquisition, sharing, transfer, application and innovation of explicit knowledge and tacit knowledge in the double team model of cross organizational service oriented comprehensive ability training are analyzed, as shown in Fig. 3, so as to enhance the service oriented comprehensive ability training and teaching effect. 


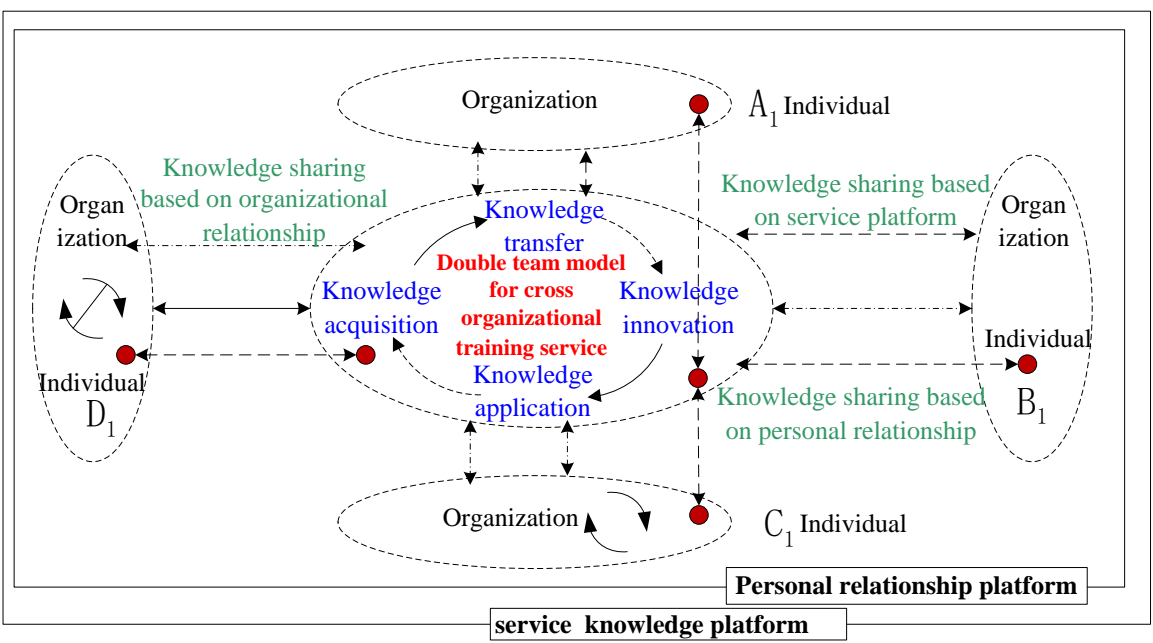

Fig. 3. Cross organizational team knowledge management model in the process of comprehensive ability training service

\section{CONCLUSION}

Based on the analysis of the present situation of the development of manufacturing service and the training needs of undergraduates' comprehensive ability, the connotation of service-oriented comprehensive ability training was put forward. The overall framework of the comprehensive ability training system was constructed, including the overall goal of the service oriented comprehensive ability training, the concept structure of the service oriented comprehensive ability training, the service content and the optimization method, the service resources and the internal correlation, the service process design, the service organization mode and the evaluation method of service quality. The teaching content, teaching platform and teaching team building module of serviceoriented comprehensive ability training system were emphatically analyzed. The teaching content, teaching platform and teaching team building module of service-oriented comprehensive ability training system were emphatically analyzed.

\section{ACKNOWLEDGMENT}

The authors gratefully acknowledge the financial support from the Wuhan University of Science and Technology Teaching and Research Project under No.2017z062 and Hubei provincial Education department humanities and social science research project under No. 18 Y026.

\section{REFERENCES}

[1] SUN Linyan, LI Gang, JIANG Zhibin,et al.Service-embedded manufacturing: advanced manufacturing paradigm in 21st century [J]. China Mechanical Engineering, 2007,18(19) :2307-2312. (In Chinese)

[2] Bai Yixian, Chen Min, Wang Ying, et al. The cultivating mode of entrepreneurial engineering talents: the engineering entrepreneurship training based on project learning [J]. Research in Higher Education of Engineering,2013(6):122-127. (In Chinese)

[3] Wei Linghui, Xu Honghai, Zhang Chaoying, et al. Exploration and practice of opening teaching method in engineering training education [J]. Experimental Technology and Management, 2015, 32(11): 191-193. (In Chinese)

[4] Zheng Hongwei, Zhang Yanrui, Ma Yuqiong, et al. Study and exploration of open laboratory with 3D printing laboratory based on innovation ability cultivation [J]. Experimental Technology and Management, 2015,32(11):159-162. (In Chinese)

[5] Zhang Dianbing. On the characteristics and reference of innovative talents cultivation mode in foreign universties $[\mathrm{J}]$. Education and Teaching Research, 2015, 29(8):1-4. (In Chinese)

[6] Wang Lei, Xia Xu-hui, Liu Xiang, et al. Combination method and application of individuation training modules for the innovation ability[J]. Laboratory Science, 2018,21(1):156-160. (In Chinese)

[7] Jin Guohua, Jin Xin, Deng Xiaowei, et al. On the cultivation mode of engineering talents in independent colleges from the perspective of panengineering [J]. Research in Higher Education of Engineering, 2012(2): 43-47. (In Chinese) 